\title{
FAKTOR-FAKTOR YANG MEMENGARUHI PRODUKSI LADA DI DESA KONGKOMOS KECAMATAN BASIDONDO KABUPATEN TOLITOLI
}

\section{FACTORS AFFECTING PEPPER PRODUCTION IN THE VILLAGE OF KONGKOMOS KECAMATAN BASIDONDO TOLITOLI DISTRICT}

\author{
Fatma $^{I}$ *, Nur Hikmah ${ }^{I}$ Usman $^{I}$ \\ ${ }^{1)}$ Program Studi Agribisnis, Sekolah Tinggi Ilmu Pertanian (STIP) Mujahidin, Tolitoli \\ Jl. Dr. Samratulangi No. 51 Tuweley Tolitoli Sulawesi Tengah
}

\begin{abstract}
ABSTRAK
Penelitian ini bertujuan untuk mengetahui faktor-faktor yang memengaruhi produksi dan besarnya faktorfaktor yang memengaruhi produksi Usahatani Lada di Desa Kongkomos Kecamatan Basidondo Kabupaten Tolitoli. Waktu penelitian dan pengumpulan data di laksanakan pada bulan Oktober sampai November 2018. Penentuan objek dan lokasi ditetapkan secara sengaja (purposive), dengan dasar pertimbangan bahwa Desa Kongkomos memiliki Produksi tertinggi di kecamatan Basidondo Kabupaten Tolitoli. Hasil penelitian menunjukkan bahwa faktor-faktor yang mempengaruhi Produksi Usahatani Lada adalah variabel luas lahan $\left(\mathrm{X}_{1}\right)$, pestisida $\left(\mathrm{X}_{2}\right)$, pupuk urea $\left(\mathrm{X}_{3}\right)$ dan tenaga kerja $\left(\mathrm{X}_{4}\right)$. Variabel $\mathrm{X}$ (luas lahan, pestisida, pupuk urea dan tenaga kerja) secara simultan berpengaruh nyata terhadap variabel $\mathrm{Y}$ (produksi lada) dengan nilai $\mathrm{R}^{2}=0,97$, yang menjelaskan bahwa kontribusi variabel $\mathrm{X}$ (luas lahan, pertisida, pupuk urea, tenaga kerja terhadap naik turunya variabel Y (produksi lada) sebesar $97 \%$ sedangkan sisanya $3 \%$ disebabkan oleh faktor lain diluar model fungsi produksi yang dianalisis. Besarnya faktor-faktor yang mempengaruhi Produksi Usahatani Lada, dari hasil uji persial mengemukakan bahwa variabel $X_{1}$ ( luas lahan) sebesar 2,968, $X_{2}$ (pestisida) sebesar 2,817, $\mathrm{X}_{3}$ (pupuk urea) sebesar 4,488 dan $\mathrm{X}_{4}$ (tenaga kerja) sebesar 3,104 lebih besar dai nilai $\mathrm{t}_{\text {tabel }}$ sebesar 2,78 yang artinya bahwa variabel $X_{1}$ (luas lahan), $X_{2}$ (pestisida), $X_{3}$ (pupuk urea) dan $X_{4}$ (tenaga kerja) berpengaruh nyata terhadap produksi lada.
\end{abstract}

Kata kunci : lada, produksi, pertanian, kongkomos.

\begin{abstract}
This study aims to determine the factors that influence production and the magnitude of the factors that affect the production of Pepper in Kongkomos Village, Basidondo District, Tolitoli Regency. The time of research and data collection was carried out from October to November 2018. The determination of the purpose and location was determined intentionally, based on the consideration that Kongkomos Village had the highest production in Tolidoli, Basidondo Regency. The results showed that the factors influencing Pepper Farming Production were variable land area (X1), pesticides (X2), urea fertilizer (X3) and labor (X4). Variable X (land area, pesticides, urea fertilizer and labor) simultaneously has a significant effect on the $Y$ variable (pepper production) with a value of $R 2=0.97$, which explains that the contribution of variable $X$ (land area, perticide, urea fertilizer, labor) ) to increase the fall of the variable $Y$ (pepper production) by $97 \%$ while the remaining $3 \%$ is caused by other factors outside the production function model analyzed. From the results of the persial test it was revealed that the variables X1 (land area) 2,968, $X 2$ (pesticides) 2,817, X3 (urea fertilizer) 4,488 and X4 (labor) 3,104 were greater than the value of t-table 2.78 which meant that the variable X1 (area land)), X2 (pesticides), X3 (urea fertilizer) and X4 (labor) have a significant effect on pepper production.
\end{abstract}

Keywords : pepper, production, farming, toli-toli, kongkomos

\footnotetext{
${ }^{\text {") }}$ Penulis Korespondensi.

E-mail: fatmahdjalal@gmail.com

HP: 082293381351
} 


\section{Latar Belakang}

Tanaman lada merupakan salah satu komoditas perdagangan dunia dan lebih dari $80 \%$ hasil produksi lada Indonesia diekspor ke luar negri. Indonesia adalah salah satu negara pengekspor lada terbesar keduadidunia. Selain itu, lada mempunyai sebutan "The King of Spice"(Raja rempah-rempah) yang mana konsumsilada di dunia tahun 2013 mencapai 472.526 ton berdasarkan data dari FAO (Food and Agriculture Organization) sedangkan total ekspor lada dunia tahun 2013 mencapai 278.126 ton, hal tersebut menunjukan bahwa peluang Indonesia untuk meningkatkan ekspor lada sangatlah besar (Badan Litbang Pertanian, 2013).

Kontribusi lada Indonesiadi pasar dunia pada tahun 2010 adalah sebesar 17\% dari produksilada dunia dan merupakan produsen lada terbesar kedua di dunia setelah Vietnam(Ditjen Perkebunan, 2011).

Lada merupakan sala satu komoditi ekspor pertanian yang menjadi andalan penghasil devisa indonesia. Sentra-sentra penghasil utama lada di indonesia adalah bangka belitung, lampung, sumatra selatan, kalimantan timur, kalimantan tengah, dan sulawesi tengah. Pada tahun 2013, produksi lada di indonesia mencapai 91,039 ton. Luas area dan produksi lada selama tahun 20132017 cenderung menurun, yaitu dari 171,920 ha pada tahun 2013 menjadi 167,622 ha pada tahun 2017, dan produksi dari 91,039 ton pada tahun 2013 menjadi 82,962 ton pada tahun 2017. Indonesia menduduki peringkat kedua negara pengespor lada terbesar di dunia dengan rata-rata volume ekspor sebesar 181,61 ribu ton (Direktorat jenderal perkebunan, 2017).

Sulawesi Tengah merupakan salah satu provinsi di indonesia yang sebagian masyarakatnya berusahatani di bidang perkebunan seperti tanaman Lada dan tanaman lainnya. Produksi tertinggi untuk Lada menurut Kabupaten di Sulawesi Tengah berada di Kabupaten Tolitoli sebesar 37,61 Ton/349,00 Ha (Dinas Perkebunan dan Peternakan Kabupaten Tolitoli, 2016). Hal ini dikarenakan usaha pembudidayaan Tanaman Lada masih tergolong baru di Kabupaten Tolitoli, sehingga Tanaman Lada yang dimiliki petani masih berusia muda dan sedang dalam produktivitas tertinggi untuk Tanaman Lada.

Di Kabupaten Tolitoli salah satu Kecamatan yang membudidayakan Tanaman Lada adalah Kecamatan Basidondo untuk memenuhi kebutuhan permintaan masyarakat yang ada di Kecamatan
Basidondo dan sekitarnya. Kecamatan Basidondo merupakan salah satu kecamatan yang ada di Kabupaten Tolitoli yang memiliki produksi tertinggi ke dua dari Kecamatan Dondo. Sebagian masyarakat Kecamatan Basidondo berprofesi sebagai petani yang bergerak di bidang tanaman perkebunan seperti budidaya tanaman Lada. Kecamatan Basidondo memiliki nilai produktivitas tertinggi kedua yaitu sebesar 0,24 ton/ha dengan luas lahan sebesar 39,00 ha dan produksi 9,36 ton. Saat ini masyarakat Kecamatan Basidondo masih membudidayakan tanaman lada, Produksi tertinggi untuk tanaman Lada di Kabupaten Tolitoli terdapat di Kecamatan Dondo yaitu sebesar 19,00 ton/ha (Dinas Perkebunan dan Peternakan Kabupaten Tolitoli, 2016).

Luas lahan rata-rata tanaman lada menurut desa di Kecamatan Basidondo 3,09 ha, dengan produksi rata-rata 0,93 ha dan produktivitas ratarata 0,24 ton/ha. Produksi tanaman lada di Desa Kongkomos adalah produksi tertinggi sebesar 9,00 Ton/18,00 Ha, di bandingkan desa lain di Kecamatan Basidondo (Badan Penyuluh Pertanian (BPP) Kecamatan Basidondo, 2016).

Tingginya produksi di Desa Kongkomos harus dipertahankan karena untuk meningkatkan kesejahtraan pendapatan, petani yang sering dihadapkan dengan keterbatasan modal, pengetahuan petani yang masih relatif rendah, lahan garapan yang sempit dan kurangnnya keterampilan petani.

\section{Metode Penelitian}

Penelitian ini adalah penelitian deskriptif kuantitatif yang bertujuan menjelaskan fenomena yang ada dengan menggunakan angka-angka untuk mencantumkan karakteristik individu atau kelompok (Syamsuddin dan Damiyanti, 2011).

Penelitian ini dilaksanakan di Desa Kongkomos Kecamatan Basidondo Kabupaten Tolitoli. Dengan pertimbangan bahwa Desa Kongkomos memiliki produksi tertinggi di Kecamatan Basidondo. Waktu penelitian dilaksanakan pada bulan Oktober sampai November 2018.

Populasi dalam penelitian ini adalah keseluruhan petani Lada yang Berdomisili di Kecamatan Basidondo yang terdapat pada Desa Kongkomos. Jumlah petani di desa tersebut bejumlah 36 orang.

Sampel adalah sebagian dari jumlah dan karakteristik yang dimiliki oleh populasi tersebut. Karena jumlah populasi petani lada yang 
Jurnal Ggratech 10 (1) 35-40, Juni 2020

berdomisili di Desa Kongkomos Kecamatan Basidondo Kabupaten Tolitoli hanya berjumlah 36 orang maka semua populasi dijadikan sampel atau di sensus.

Penelitian ini menggunakan data yang bersumber dari data primer dan data skunder. Data primer adalah data yang bersal dari hasil observasi dan wawancara langsung kepada petani lada dengan menggunakan kuisoner sebagai alat bantu. Data sekunder adalah data penunjang yang di peroleh dari instansi dan lembaga pemerintahan yang berkaitan dengan penelitaian ini seperti Kantor Statistik dan Dinas Tanaman Pangan dan Hortikultura Kabupaten Tolitoli.

Penelitian ini menggunakan analisis fungsi Produksi Cobb-Douglas adalah suatu fungsi atau persamaan yang melibatkan dua variabel, dimana variabel yang satu disebut dengan variabel dependen (yang dijelaskan/Y), dan yang lainnya disebut variabel independen (yang menjelaskan/X) (Soekartawi, 1993).

Sesuai dengan variabel yang akan diteliti maka persamaan dapat ditulis sebagai berikut :

$$
\begin{gathered}
\ln Y=\ln b o+b_{1} \ln \chi_{1}+b_{2} \ln \chi_{2}+b_{3} \ln \chi_{3} \\
+b_{4} \ln \chi_{4}+\mu
\end{gathered}
$$

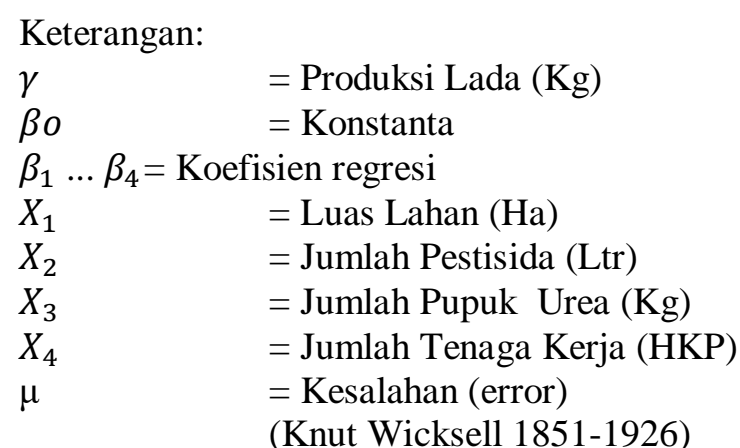

\section{Hasil dan Pembahasan}

\section{Hasil}

\section{Keadaan Usahatani}

\section{Luas Lahan Usahatani}

Luas penguasaan lahan pertanian merupakan salah satu faktor yang penting dalam meningkatkan produksi usahataninya sehingga pendapatan dapat meningkat pula. Semakin besar bertambahnya luas lahan yang digarap serta ditunjang dengan penerapan teknologi usahatani yang tepat, cenderung akan memberikan produksi yang makin tinggi.

Tabel 1. Luas Lahan Yang Digarap Petani Responden Usahatani Lada Desa Kongkomos Kecamatan
e-ISSN : 2621-7236

p-ISSN : 1858-134X

Basidondo Kabupaten Tolitoli, Tahun

\begin{tabular}{lcrr}
\hline N & Luas Lahan & Jumlah (Jiwa) & Persentasi (\%) \\
0 & Garapan (Ha) & & \\
\hline 1 & $\leq 1.00$ & 21 & 61.11 \\
2 & $>1.00$ & 15 & 38.89 \\
\hline Jumlah & 36 & 100.00 \\
\hline \multicolumn{5}{c}{2017.}
\end{tabular}

Sumber : Diolah dari data primer, 2017

Tabel 1 menunjukkan bahwa hasil observasi dan wawancara langsung dengan $36 \mathrm{KK}$ responden petani lada diketahui bahwa luas lahan yang digarap untuk tanaman lada kurang dari 1,00 ha berjumlah 21 jiwa dengan presentase $61,11 \%$, dan yang petani responden yang mempunya luas lahan lebih dari 1,00 ha berjumlah 15 jiwa dengan presentase $38,89 \%$. hal ini menunjukkan bahwa rata-rata luas lahan petani responden Desa Kongkomos Kecamatan Basidondo Kabupaten Tolitoli adalah 1,14 ha.

\section{Penggunaan Pupuk}

Pada daerah penelitian Desa Kongkomos Kecamatan Basidondo Kabupaten Tolitoli, petani responden semua menggunakan Pupuk Urea. Ratarata penggunaan pupuk Urea $0,19 \mathrm{~kg}$, penggunaan pupuk oleh petani responden di Desa Kongkomos Kecamatan Basidondo masih rendah yang dianjurkan dengan takaran 1,00 kg/pohon. Dalam memberikan pupuk saat bertanam lada juga dapat ditambahkan formulasi pupuk yang terdiri dari campuran mikroba yang menguntungkan. Hal ini dilakukan dengan tujuan meningkatkan kesehatan tanaman lada tersebut. Secara umum, tahun pertama lada menggunakan $5 \mathrm{~kg}$ bahan organik/pabrik dan pupuk anorganik sebanyak 100 gram/tahun. Distribusi pupuk anorganik itu sendiri telah dibagi menjadi empat kali, yaitu 30 gram, 60 gram, 90 gram dan 120 gram dengan interval 3 bulan. Pemupukan tanaman lada ini sebaiknya dilakukan pada saat musim hujan sehingga pertumbuhan tanaman lada tersebut akan lebih maksimal dan memuaskan dalam memetik hasil panennya.

\section{Penggunaan Pestisida}

Pestisida merupakan bahan kimia yang digunakan untuk mengontrol hama tanaman budidaya, sebagian besar beraksi dengan cara mengganggu proses dasar biokimia dan fisiologi suatu organisme. Penyemprotan pestisida harus dilaksanakan pada saat yang tepat sehubungan dengan tahap-tahap perkembangan hama. Cara 
penggunaan pestisida bermacam-macam, antara lain dengan cara disemprotkan, ditaburkan, diinjeksikan pada batang dan ada pula dengan cara pengasapan. Pada umumnya pestisida digunakan melalui penyemprotan. Pestisida yang digunakan petani responden di Desa Kongkomos Kecamatan Basidondo yaitu Gramaxone untuk tanaman penggangu di sekitar tanaman lada dengan rata-rata 2,08 liter/ha.

\section{Penggunaan Tenaga Kerja}

Penggunaan tenaga kerja dapat dinyatakan sebagai curahan tenaga kerja. Curahan tenaga kerja adalah besarnya tenaga kerja efektif yang digunakan. Ukuran tenaga kerja dapat dinyatakan dalam hari orang kerja (HOK). Tenaga kerja yang digunakan petani responden adalah tenaga kerja yang berasal dari dalam keluarga berjumlah 79 orang.

Cara mencari hari orang kerja (HOK) yaitu jumlah tenaga kerja, hari kerja dan jam kerja dikalikan kemudian dibagi 8 jam sebagai satuan HOK atau lebih jelasnya dengan rumus :

$\mathrm{HOK}=($ tenaga kerja $\mathrm{x}$ hari kerja $\mathrm{x}$ jam kerja perhari)/ 8 jam

Kemudian mendapatkan hasil dengan rata-rata pengolahannya 2,19 HOK 11,47, pemupukan 2,19 HOK 10,50, pemeliharaan 2,19 HOK 10,14 dan panen 2,19 HOK 10,60.

\section{Pembahasan}

\section{Analisis Usahatani}

\section{Produksi Usahatani}

Bishop dan Toussaint (1992), mengemukakan produksi adalah suatu proses dimana beberapa barang dan jasa yang disebut input diubah menjadi barang dan jasa lain yang disebut output. Jumlah produksi lada di Desa Kongkomos Kecamatan Basidondo Kabupaten Tolitoli rata-rata per ha mencapai $1.214,47 \mathrm{~kg}$.

\section{Analisis Faktor-faktor yang Mempengaruhi Produksi Lada}

Upaya untuk memaksimalkan produksi dalam berusahatani lada antara lain dengan memanfaatkan faktor sosial ekonomi produksi secara optimum. Faktor-faktor sosial ekonomi yang diidentifikasikan dapat mempengaruhi produksi lada adalah luas lahan, pupuk, petisida dan tenaga kerja. Estimasi mengenai pengaruh input produksi terhadap produksi secara umum dilakukan dengan menggunakan Analisis Regresi Linier Berganda yaitu suatu fungsi atau persamaan yang melibatkan 2 variabel atau lebih. Variabel satu disebut variabel dependen yang dijelaskan (Y) dan yang lain disebut variabel independen, yang menjelaskan (X).

Untuk melihat pengaruh varibel independen (X) terhadap secara simultan terhadap variabel dependen (Y) digunakan Uji F (F-test), untuk lebih jelasnya terlihat pada tabel 2 .

Tabel 2. Anova (analysis of variance) Input-input yang

\begin{tabular}{|c|c|c|c|c|c|c|}
\hline & Model & $\begin{array}{l}\text { Sum } \\
\text { of } \\
\text { Squar } \\
\text { es }\end{array}$ & df & $\begin{array}{c}\text { Mean } \\
\text { Squar } \\
\text { e }\end{array}$ & $\mathrm{F}_{\text {-count }}$ & $\mathrm{R}^{2}$ \\
\hline & $\begin{array}{l}\text { Regresio } \\
n\end{array}$ & 7.250 & 4 & 1.813 & 55.535 & 0.97 \\
\hline 1 & $\begin{array}{l}\text { Residual } \\
\text { Total }\end{array}$ & $\begin{array}{l}1.012 \\
8.262\end{array}$ & $\begin{array}{l}31 \\
35\end{array}$ & .0 .33 & & \\
\hline
\end{tabular}

F-tabel $(5 \%)=2.68$

Sumber : Hasil Analisis Data Primer Setelah Diolah, Tahun 2017

Tabel 2 dari Anova (analisis of variance) diperoleh nilai F-hitung sebesar 55,535 lebih besar dari F-tabel $\alpha 5 \%$ sebesar 2,68. Ini berarti bahwa variabel (Luas lahan, Pupuk Urea, Pestisida dan Tenaga Kerja) secara bersama-sama berpengaruh nyata terhadap produksi lada hal tersebut dapat dilihat pada uji ketepatan model dengan Koefisisen Determinasi $\left(\mathrm{R}^{2}\right)$ mencapai 0,97 yang berarti bahwa variasi luas lahan, pupuk urea, pestisida dan tenaga kerja dapat menjelaskan variasi produksi lada $97 \%$ sedangkan sisanya $3 \%$ disebabkan faktor lain diluar model fungsi produksi yang dianalisis. Nilai koefisien korelasi 0,97 menunjukkan bahwa, keeratan hubungan antara varibel (X) dan tingkat produksi (Y) mencapai 97 $\%$. Namun untuk melihat pengaruh dari masingmasing variabel bebas terhadap tingkat produksi lada, harus dilakukan dengan analisisis parsial sebagai berikut.

Tabel 3. Koefisien Regresi Berganda dari beberapa Faktor yang Mempengaruhi Produksi Lada Desa Kongkomos, Tahun 2017

\begin{tabular}{|c|c|c|c|c|}
\hline Variabel & $\begin{array}{l}\text { Koefisi } \\
\text { en } \\
\text { Sig. } \\
\text { Regres } \\
\text { i } \\
\end{array}$ & $\begin{array}{c}\text { t- } \\
\text { Hitu } \\
\text { ng }\end{array}$ & $\begin{array}{c}\begin{array}{c}\text { t- } \\
\text { tabel }\end{array} \\
\alpha= \\
5 \%\end{array}$ & $\begin{array}{c}\text { Sig. } \\
\text { Std. } \\
\text { Erro } \\
\text { r }\end{array}$ \\
\hline Konstanta & 10.514 & 7.379 & 2.78 & 0.001 \\
\hline Luas lahan $X_{1}$ & 1.364 & 2.968 & 2.78 & 0.001 \\
\hline Pestisida $\mathrm{X}_{2}$ & 0.185 & 2.817 & 2.78 & 0.321 \\
\hline Pupuk urea $X_{3}$ & 0.166 & 4.488 & 2.78 & 0.315 \\
\hline Tenaga kerja $\mathrm{X}_{4}$ & 0.724 & 3.104 & 2.78 & 0.225 \\
\hline \multicolumn{5}{|l|}{$\mathrm{R}^{2}=0.97$} \\
\hline $\mathrm{N}=36$ & & & & \\
\hline
\end{tabular}


Sumber : Hasil Analisis Data Primer Setelah Diolah, Tahun 2017

Tabel 3 Menunjukkan hasil Analisis Regresi Berganda (Multiple Regresion Analysis) diperoleh koefisisen dan persamaan regresi yang menunjukkan bahwa hasil pengujian T-test dari 4 variabel yang berpengaruh nyata terhadap produksi yaitu terlihat pada persamaan regresi sebagai berikut :

$$
\begin{gathered}
\text { Ln } Y=10,514+1,364 X_{1}+0,185 X_{2}+0,166 \\
X_{3}+0,724 X_{4}
\end{gathered}
$$

Besar pengaruh variabel independen (X) terhadap variabel dependen (Y), yang menunjukkan dari nilai koefisien regresinya. Pengaruh masing-masing input produksi terhadap produksi lada adalah :

\section{(1) Luas Lahan $\left(X_{1}\right)$}

Berdasarkan hasil analisis regresi ini menunjukkan bahwa luas lahan (X1), berpengaruh nyata terhadap produksi lada (Y) pada taraf kepercayaan 97\%, hal ini terlihat dari nilai $\mathrm{T}_{\text {-hitung }}$ sebesar 2,968 lebih besar dari $\mathrm{T}$-tabel sebesar 2,78. Nilai koefisien rekresi sebesar 1,364 yang artinya bahwa setiap terjadi penambahan luas lahan sebesar $1 \%$ menyebabkan kenaikan produksi sebesar $1,364 \%$ lada dengan asumsi bahwa faktor lain dianggap konstan. Variabel luas lahan mempunyai pengaruh positif dan signifikan terhadap jumlah produksi sehingga Ho ditolak dan H1 diterima.

Hasil penelitian ini sejalan dengan penelitian Sulolipu, (2016) yang menunjukkan bahwa faktor produksi berupa luas lahan berpengaruh positif dan signifikan terhadap produksi lada di Desa Swatani Kecamatan Rilau Ale Kabupaten Bulukumba.

\section{(2) Pestisida $\left(\mathbf{X}_{2}\right)$}

Berdasarkan hasil analisis regresi ini menunjukkan bahwa pestisida $\left(\mathrm{X}_{2}\right)$, berpengaruh untuk mempertahankan produksi lada (Y) pada taraf kepercayaan 97\%, hal ini terlihat dari nilai Thitung sebesar 2,817 lebih besar dari $\mathrm{T}$-tabel sebesar 2,78. Nilai koefisien sebesar 0,185 yang artinya bahwa setiap penambahan pestisida sebesar $1 \%$ mempertahankan produksi sebanyak $0,185 \%$ lada dengan asumsi bahwa faktor lain dianggap konstan. Variabel pestisida mempunyai pengaruh terhadap jumlah produksi sehingga Ho ditolak dan H1 diterima.

Hasil penelitian ini sejalan dengan penelitian Sulolipu, (2016) yang menunjukkan bahwa faktor produksi pestisida secara simultan berpengaruh positif dan signifikan terhadap produksi lada di Desa Swatani Kecamatan Rilau Ale Kabupaten Bulukumba.

\section{(3) Pupuk Urea $\left(\mathbf{X}_{3}\right)$}

Berdasarkan hasil analisis regresi ini menunjukkan bahwa pupuk $\left(\mathrm{X}_{3}\right)$, berpengaruh nyata terhadap produksi lada (Y) pada taraf kepercayaan $97 \%$, hal ini terlihat dari nilai $\mathrm{T}_{\text {-hitung }}$ sebesar 4,488 lebih besar dari $\mathrm{T}_{\text {-tabel }}$ sebesar 2.78 . Nilai koefisien regresi sebesar 0,16 yang artinya bahwa setiap terjadi penambahan pupuk sebesar 1 $\%$ menyebabkan kenaikan produksi sebanyak $0,166 \%$ lada dengan asumsi bahwa faktor lain dianggap konstan. Variabel luas lahan mempunyai pengaruh positif dan signifikan terhadap jumlah produksi sehingga Ho ditolak dan H1 diterima.

Hasil penelitian ini sejalan dengan penelitianWirya Purba, (2015) yang menayatakan bahwa kondisi penggunaan faktor produksi secara teknis efisien pada dosis pupuk Urea. Hasil penelitian Nurmala, Dkk (2015) menyatakan bahwa variabel pupuk urea berpengaruh nyata terhadap produksi usahatani cengkeh di Kecamatan Dako Pemean.

\section{(4) Tenaga Kerja $\left(\mathbf{X}_{4}\right)$}

Berdasarkan hasil analisis regresi ini menunjukkan bahwa tenaga kerja (X4), berpengaruh nyata terhadap produksi lada (Y) pada taraf kepercayaan $97 \%$, hal ini terlihat dari nilai $\mathrm{T}_{\text {-hitung }}$ sebesar 3,104 lebih besar dari $\mathrm{T}_{\text {-tabel }}$ sebesar 2,78. Nilai koefisien regresi yang artinya bahwa setiap terjadi penambahan tenaga kerja sebesar $1 \%$ menyebabkan kenaikan produksi sebanyak $0,724 \%$ lada dengan asumsi bahwa faktor lain dianggap konstan. Variabel pestisida mempunyai pengaruh terhadap produksi sehingga Ho ditolak dan $\mathrm{H} 1$ diterima.

Hasil penelitian ini sejalan dengan penelitian Pranoto (2016) menunjukkan bahwa tenaga kerja berpengaruh terhadap produksi lada di Desa Kundi Kecamatan Simpang Tertitip Kabupaten Bangka Barat.

\section{Kesimpulan dan Saran}

\section{Kesimpulan}

Berdasarkan dari hasil penelitian, maka dapat di tarik kesimpulan berdasarkan dari hasil analisis menunjukkan bahwa faktor-faktor yang mempengaruhi Produksi Usahatani Lada di Desa Kongkomos Kecamatan Basidondo adalah variabel luas lahan $\left(\mathrm{X}_{1}\right)$, pestisida $\left(\mathrm{X}_{2}\right)$, pupuk urea $\left(\mathrm{X}_{3}\right)$ dan tenaga kerja $\left(\mathrm{X}_{4}\right)$. 


\section{Saran}

1. Petani dapat lebih memperhatikan penggunaan input produksi seperti : Luas lahan, Pestisida, Pupuk dan Tenaga Kerja karena secara langsung dapat meningkatkan Produksi Lada.

2. Untuk menjaga hasil produksi lada agar tetap meningkat diharapkan petani lada memenuhi input-input produksi terutama pemenuhan unsur hara pada tanaman lada berupa pemberian pupuk sehingga mampu menghasilkan produksi dan menambah penghasilanpetani lada

\section{Daftar Pustaka}

Andi A, S. 2016. Melakukan penelitian Pengaruh Faktor-Faktor Produksi Pada Usahatani Lada Di Desa Swatani Kecamatan Rilau Ale Kabupaten Bulukumba. Jurnal Administrare, Volume 3 No.2, 2016.

Abas, A., Noer, H. \& If'all (2019). Faktor-Faktor Yang Mempengaruhi Produksi Tanaman Padi Gogo Di Kabupaten Morowali. Jurnal Agrotech, 9(1), 16-25.

Badan Litbang Pertanian. 2013. Peningkatan Ekspor Pada Tanaman Lada (Piper Ningrum L). Bogor : Teknologi Pertanian.

Badan Penyuluh Pertanian. 2016. Kecamatan Basidondo. Kabupaten Tolitoli dalam angka Tahun 2016. Tolitoli

Bishop dan Toussaint. 1992. Proses produksi. Melalui https://googleweblight.com. (30/01/2019).

Dinas Perkebunan dan Peternakan. 2016. Kabupaten Tolitoli dalam angka Tahun 2016. Tolitoli.
p-ISSN : 1858-134X

Direkotarat Jendral Perkebunan. 2011. Kontribusi lada di Dunia. Skripsi. Fakultas Teknologi Pertanian, Bogor : InstitutPertanian.

Direktorat Jendra Perkebunan. 2017. Lada salah satu komoditi ekspor pertanian yang menjadi andalan penghasil devisa indonesia. Jakarta : Departemen Pertanian.

Knut Wicksel. 1851- 1926. Fungksi Produksi Model Coob Douglass. Melalui https://googleweblight.Com. (10/10/2018).

Nurmala, M. Antara Dan Hadayani. Efficiency Analysis of Production Input Uses of Clove Farming in Dako Pemean Sub District of Tolitoli Regency. Jurnal Agroland 22 (3) : 226 - 234, Desember 2015

Soekartawi. 1993. Fungsi produksi Cobb-Douglass Melalui https://googleweblight.Com. (10/10/2018).

Syamsuddin dan Damiyanti. 2011. Deskriptif Kuantitatif.

Melalui https://googleweblight.Com. (10/10/2018).

Yudi S, P. 2016. Pengaruh Faktor Produksi Pada Usahatani Lada di Desa Kundi Kecamatan Simpang Tertitip Kabupaten Bangka Barat. Jurnal Agraris. Volume. 2 No. 1 Januari 2016.

Yudhi Z, W. 2015. Hasil analisis efisiensi teknis pada penggunaan lahan dan tenaga kerja. Skripsi. Sumatra selatan : Program Studi Agribisnis Fakultas Pertanian Universitas Sriwijaya. 